\title{
STUDY OF ASSOCIATION OF SERUM URIC ACID WITH ALBUMINURIA IN TYPE II DIABETES MELLITUS
}

\author{
Priti Sambhaji Langote1, Mallanna Shankreppa Mulimani²
}

${ }_{1}^{1}$ Post Graduate Student, Department of Medicine, Shri B. M. Patil Medical College, Hospital and Research Centre, Vijayapur.

${ }_{2}^{2}$ HOD and Professor, Department of Medicine, Shri B. M. Patil Medical College, Hospital and Research Centre, Vijayapur.

\section{ABSTRACT}

\section{BACKGROUND AND OBJECTIVES}

Diabetic Nephropathy (DN) is the most common cause of chronic kidney disease worldwide. ${ }^{1-2}$ In the wake of the current epidemic of Diabetes Mellitus (DM), the prevalence of DN and End-Stage Renal Disease (ESRD) is projected to rise. ${ }^{3}$ Different therapeutic strategies targeting DN have been explored such as tight glycemic control. ${ }^{4}$ tight blood pressure control. ${ }^{5}$ and various inhibitors of the Renin Angiotensin Aldosterone System (RAAS). ${ }^{6-8}$ while these therapies appear to slow the progression of kidney disease due to diabetes, none of them are curative. Thus we require adjunctive therapeutic strategies, especially in patients with complications of treatment or lack of appropriate response. ${ }^{9}$ hence, there is a pressing interest to identify other potentially modifiable factors in the progression of DN. Inflammation and endothelial dysfunction appear to play a central role in the onset and the progression of DN. Recent evidence has emerged in the last decade to suggest uric acid is an inflammatory factor and may play a role in endothelial dysfunction. Studies suggest that treatment of diabetic nephropathy may be benefited by treatment with xanthine oxidase inhibitor. ${ }^{10}$ The aim of this study is to find an association between serum uric acid level and albuminuria in Type 2 Diabetes Mellitus (T2DM).

\section{METHODS}

This study was carried out in B.L.D.E.U's Shri B.M. Patil Medical College Hospital and Research Centre, Vijayapur, Karnataka; during the period from December 2013 to July 2015. A total of 56 patients who were known case of type 2 diabetes mellitus were included in the study. The blood of the selected subjects were analysed for serum uric acid and urine albumin creatinine ratio.

\section{RESULTS}

Serum uric acid levels for and

1. Normoalbuminuric patients $=4.09 \pm 1.36 \mathrm{mg} / \mathrm{dL}$.

2. Microalbuminuric patients $=5.21 \pm 1.60 \mathrm{mg} / \mathrm{dL}$.

3. Macroalbuminuric patients $=7.38 \pm 0.87 \mathrm{mg} / \mathrm{dL}$.

Serum uric acid level correlated positively with urinary albumin creatinine ratio $(r=0.559, p=<0.001)$

\section{CONCLUSION}

Serum uric acid had a significant positive correlation with albuminuria in type 2 diabetes mellitus.

\section{KEYWORDS}

Uric Acid, Albuminuria, Diabetes, Association, Type 2 Diabetes.

HOW TO CITE THIS ARTICLE: Langote PS, Mulimani MS. Study of association of serum uric acid with albuminuria in type II diabetes mellitus. J. Evolution Med. Dent. Sci. 2016;5(16):769-773, DOI: 10.14260/jemds/2016/179

\section{INTRODUCTION}

Diabetic Nephropathy (DN) is the most common cause of chronic kidney disease worldwide. ${ }^{1-2}$ In the wake of the current epidemic of Diabetes Mellitus (DM), the prevalence of DN and End-Stage Renal Disease (ESRD) is projected to rise. ${ }^{3}$

Uric acid is a common risk factor for vascular diseases. ${ }^{4}$ hypertension. ${ }^{5}$ type 2 diabetes mellitus and diabetic nephropathy. ${ }^{6}$ Hyperuricemia has an association with type 2 diabetes mellitus and hypertension independently of each other.

Though the cause and effect relationship of hyperuricemia and diabetic nephropathy is debatable; however, some literature mentions the detrimental effects of high uric acid level on the kidney functions. ${ }^{7}$

Financial or Other, Competing Interest: None.

Submission 15-01-2016, Peer Review 09-02-2016,

Acceptance 15-02-2016, Published 24-02-2016.

Corresponding Author:

Dr. Priti Sambhaji Langote,

C/o., S. S. Hiremath,

Rambhapuri Nilaya,

Vidya Nagar, Near BLDE Campus,

Vijayapur-586103.

E-mail: pritisl2011@gmail.com

DOI: $10.14260 /$ jemds/2016/179
The main detrimental effect of high uric acid level as a part of the obesity and metabolic syndrome is through its injurious effects on the endothelium and inducing chronic inflammation. ${ }^{8}$

Accumulating data reveal that inflammation, endothelial dysfunction and procoagulant imbalance are associated with nephropathy, retinopathy and cardiovascular disease in Diabetes Mellitus (DM). ${ }^{9-11}$ The association of serum UA levels and dyslipidemia with inflammation and endothelial dysfunction are also shown.12,13 However, the putative association between serum UA levels and albuminuria is not clear.

Studies suggest that treatment of diabetic nephropathy may be benefited by treatment with xanthine oxidase inhibitor. ${ }^{14}$

The aim of this study is to find an association between serum uric acid level and albuminuria in Type 2 Diabetes Mellitus (T2DM).

\section{MATERIALS AND METHODS}

A cross-sectional study is conducted on type 2 diabetic patients attending the outpatient department and being admitted to our Hospital from December 2013 to July 2015. 
With the prevalence rate of overt nephropathy in Diabetes Mellitus 2.2\%. ${ }^{15}$ at $99 \%$ confidence interval and at \pm 5 margin of error the sample size is 56 .

$\mathrm{N}=(2.56)^{2} * \mathrm{P} * \mathrm{Q} / \mathrm{d}^{2}$

Hence, 56 cases of type 2 diabetes mellitus are included in the study to associate serum uric acid level with albuminuria.

Data is analysed using,

- Diagrammatic presentation.

- Mean \pm SD.

- Correlation coefficient.

- Linear and multiple regression analysis.

A detailed history, physical examination including blood pressure, BMI, current medications, insulin doses, habits like tobacco and alcohol consumption and family medical history is obtained from all the patients coming to the hospital with type 2 diabetes mellitus.

The biochemical investigations like examination of urine, serum uric acid, serum creatinine, $\mathrm{HbA1C}$ is estimated and urine albumin and urine creatinine are measured.

Patients with known case of type 2 diabetes mellitus were included in this study and patients who are on treatment with uric acid lowering agents/diuretics, history of gout/acute febrile illness/UTI/CML/Cancer were excluded from the study.

After obtaining informed and written consent venous blood is collected from each subject and transported to the laboratory. Random spot urine sample is collected at the same time.

Urine Albumin Concentration (UAC) is measured by turbidimetric immunoassay and is expressed as urine albumin creatinine ratio (ACR). Urinary ACR is calculated by dividing UAC in micrograms by urinary creatinine concentration in milligrams.

1. ACR $=30.0 \mu \mathrm{g} / \mathrm{mg}$ or lower is considered as "normal,"

2. ACR between $30 \mu \mathrm{g} / \mathrm{mg}$ and $299 \mu \mathrm{g} / \mathrm{mg}$ is considered as "microalbuminuria."

3. Very high ratio (ACR $\geq 300 \mu \mathrm{g} / \mathrm{mg}$ ) is defined as "overt albuminuria."

Serum uric acid level is measured by uricase peroxidase method (Liqui CHEK, AGAPPE). Enzymatic determination is done according to following reaction.

Uric acid $+2 \mathrm{H}_{2} \mathrm{O}+\mathrm{O}_{2} \underset{\text { uricase }}{\longrightarrow}$ Allontoine $+\mathrm{CO}_{2}+\mathrm{H}_{2} \mathrm{O}_{2}$ $2 \mathrm{H}_{2} \mathrm{O}_{2}+4$-Aminoantipyrine + EHSPT $\stackrel{\text { peroxidase }}{\longrightarrow}$ Red quinone.

EHSPT $=\mathrm{N}$-Ethyl N-(2-Hydroxy-3-Sulfoproyl) n-Toluidine.

All the subjects are subjected to the following investigations

1. Urine Examination.

2. Serum Creatinine.

3. Serum Uric Acid.

4. HbA1C.

5. Urine Albumin.

6. Urine Creatinine.

7. Random Blood Sugar (RBS) Level.

8. Fasting Blood Sugar (FBS) Level.

9. Post Prandial Blood Sugar (PPBS) Level.

10. HIV Rapid Test.

\section{RESULTS}

Clinical characteristics of 56 patients with type2 DM enrolled in this study are shown in Table 1.

\begin{tabular}{|c|c|c|}
\hline $\begin{array}{c}\text { Sr. } \\
\text { No. }\end{array}$ & Parameters & Value (Mean \pm SD) \\
\hline 1 & Age(years) & $56.61 \pm 12.11$ \\
\hline 2 & Gender I. Male & $29(52 \%)$ \\
& II. Female & $27(48 \%)$ \\
\hline 3 & BMI $\left(\mathrm{kg} / \mathrm{m}^{2}\right)$ & $23.82 \pm 3.43$ \\
\hline 4 & SBP $(\mathrm{mmHg})$ & $137.86 \pm 14.36$ \\
\hline 5 & DBP $(\mathrm{mmHg})$ & $81.39 \pm 6.86$ \\
\hline \multirow{2}{*}{6} & Duration of & $6.63 \pm 4.03$ \\
\hline 7 & duration $($ years $)$ & $5.11 \pm 1.70$ \\
\hline 8 & SUA(mg/dL) & $1.05 \pm 0.40$ \\
\hline 9 & Sr. Creatinine(mg/dL) & $7.30 \pm 2.34$ \\
\hline 10 & HbA1C $(\%)$ & $96.05 \pm 91.56$ \\
\hline \multicolumn{2}{|c|}{ Table 1: Characteristics of the study population } \\
\hline \multicolumn{2}{|c|}{} \\
\hline
\end{tabular}

Out of 56 patients, males and females were $29(52 \%)$ and $27(48 \%)$, respectively. The mean age of the patients included in this study was $56.61 \pm 12.11$ years and mean duration of diabetes of the patients was $6.63 \pm 4.03$ years. The mean body mass index of study population was $23.82 \pm 3.43 \mathrm{~kg} / \mathrm{m}^{2}$, while the mean serum uric acid concentration observed in study population was $5.11 \pm 1.70 \mathrm{mg} / \mathrm{dL}$.

The mean uric acid concentration was $5.11 \pm 1.70 \mathrm{mg} / \mathrm{dL}$, which was higher in men than in women $(5.12 \pm 1.50 \mathrm{mg} / \mathrm{dL}$ versus $5.09 \pm 1.92 \mathrm{mg} / \mathrm{dL}$, respectively) But there was no statistically significant difference in serum uric acid concentration between males and females $(\mathrm{P}=0.939)$.

The mean value of Normoalbuminuria, Microalbuminuria and Macroalbuminuria in the enrolled patients was $17.54 \pm 5.53,96.53 \pm 52.4$ and $327.43 \pm 32.6$, respectively.

\begin{tabular}{|c|c|c|c|}
\hline Parameter & $\begin{array}{c}\text { Norm } \\
\text { albuminuria }\end{array}$ & $\begin{array}{c}\text { Micro } \\
\text { albuminuria }\end{array}$ & $\begin{array}{c}\text { Macro } \\
\text { albuminuria }\end{array}$ \\
\hline Age & $54.53 \pm 12.96$ & $56.69 \pm 12.10$ & $62.20 \pm 9.63$ \\
\hline Male & $10(67 \%)$ & $16(44 \%)$ & $3(60 \%)$ \\
\hline Female & $5(33 \%)$ & $20(55 \%)$ & $2(40 \%)$ \\
\hline BMI & $23.41 \pm 2.46$ & $24.17 \pm 3.84$ & $22.60 \pm 2.81$ \\
\hline HTN & $0(0 \%)$ & $9(25 \%)$ & $4(80 \%)$ \\
\hline SBP & $133.87 \pm 10.89$ & $137.28 \pm 13.32$ & $154.00 \pm 21.91$ \\
\hline DBP & $80.27 \pm 5.60$ & $80.94 \pm 6.82$ & $88.00 \pm 8.37$ \\
\hline HbA1C & $5.81 \pm 1.50$ & $7.76 \pm 2.37$ & $8.40 \pm 2.60$ \\
\hline $\begin{array}{c}\text { Duration } \\
\text { of DM }\end{array}$ & $4.93 \pm 2.55$ & $6.44 \pm 3.67$ & $13.00 \pm 4.70$ \\
\hline $\begin{array}{c}\text { Serum } \\
\text { Creatinine }\end{array}$ & $0.95 \pm 0.41$ & $1.06 \pm 0.36$ & $1.30 \pm 0.58$ \\
\hline SUA & $4.09 \pm 1.36$ & $5.21 \pm 1.60$ & $7.38 \pm 0.87$ \\
\hline
\end{tabular}

Table 2: All parameters compared with ACR classification

In this study it is found that 9 (25\%) of microalbuminuric and $4(80 \%)$ of macroalbuminuric patients were having hypertension (Table 2).

The mean HbA1C was more in macroalbuminuric patients $(8.40 \pm 2.60)$ than in microalbuminuric patients (7.76 \pm 2.37 ), while in patients with normoalbuminuria, it was found to be $5.81 \pm 1.50$. 


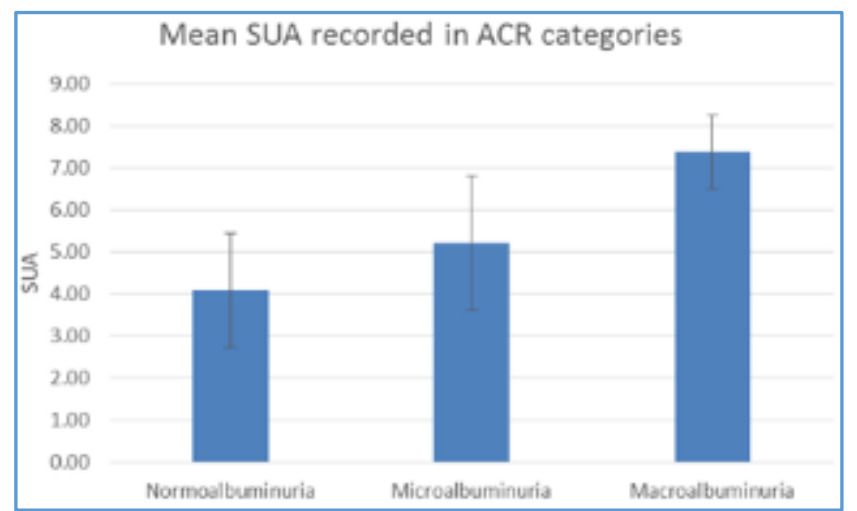

Graph 1: Mean Serum uric acid (mg/dL) in ACR categories

It is found that concentration of serum uric was $4.09 \pm 1.36, \quad 5.21 \pm 1.60$ and $7.38 \pm 0.87$ in patients with normoalbuminuria, microalbuminuria and macroalbuminuria, respectively. While considering normoalbuminuria and abnormal albuminuria, serum uric acid concentration was $4.09 \pm 1.6$ and $5.48 \pm 1.68$, respectively.
It was found that there was statistically significant and positive correlation between serum uric acid concentration and albumin creatinine ratio $(\mathrm{r}=0.559, \mathrm{p}<0.001)$ in the enrolled type 2 diabetic patients.

Duration of diabetes was also positively correlated with albumin creatinine ratio. It was also statistically significant $(\mathrm{r}=0.526, \mathrm{P}<0.001)$.

Also, it was found positive and statistically significant correlation between $\mathrm{HbA} 1 \mathrm{C}$ and albumin creatinine ratio ( $\mathrm{r}=0.429, \mathrm{p}=0.001)$.

The correlation between BMI and ACR was found to be almost nil $(\mathrm{r}=-0.001)$ and was not statistically significant $(\mathrm{P}>0.05)$, while SBP showed statistically significant correlation with albumin creatinine ratio $(p=0.001)$

Only those parameters which were found to be significantly correlated with ACR are used in regression. By linear regression, variations in ACR are estimated using different parameters individually.

Considering the $\mathrm{R}^{2}$ (Coefficient of determination) value, serum uric acid is found to be a significant factor which could predict only $31.2 \%\left(\mathrm{R}^{2}=0.312\right)$ variation in albumin creatinine ratio.

\begin{tabular}{|c|c|c|c|}
\hline $\begin{array}{c}\text { Sl. } \\
\text { No. }\end{array}$ & Parameters & $\begin{array}{c}\text { Correlation } \\
\text { coefficient ' } \mathbf{r} \text { ' }\end{array}$ & 'p' value \\
\hline 1 & Age & 0.214 & 0.113 \\
\hline 2 & BMI & -0.001 & 0.994 \\
\hline 3 & SBP & 0.431 & $0.001^{*}$ \\
\hline 4 & DBP & 0.254 & 0.059 \\
\hline 5 & $\begin{array}{c}\text { Duration of } \\
\text { Diabetes (years) }\end{array}$ & 0.526 & $<0.001^{*}$ \\
\hline 6 & Serum Uric Acid & 0.559 & $<0.001^{*}$ \\
\hline 7 & Serum Creatinine & 0.310 & $0.020^{*}$ \\
\hline 8 & HbA1C & 0.429 & $0.001^{*}$ \\
\hline \multicolumn{2}{|c|}{ (ACR) and other parameters } \\
\hline
\end{tabular}

* denotes significant correlation

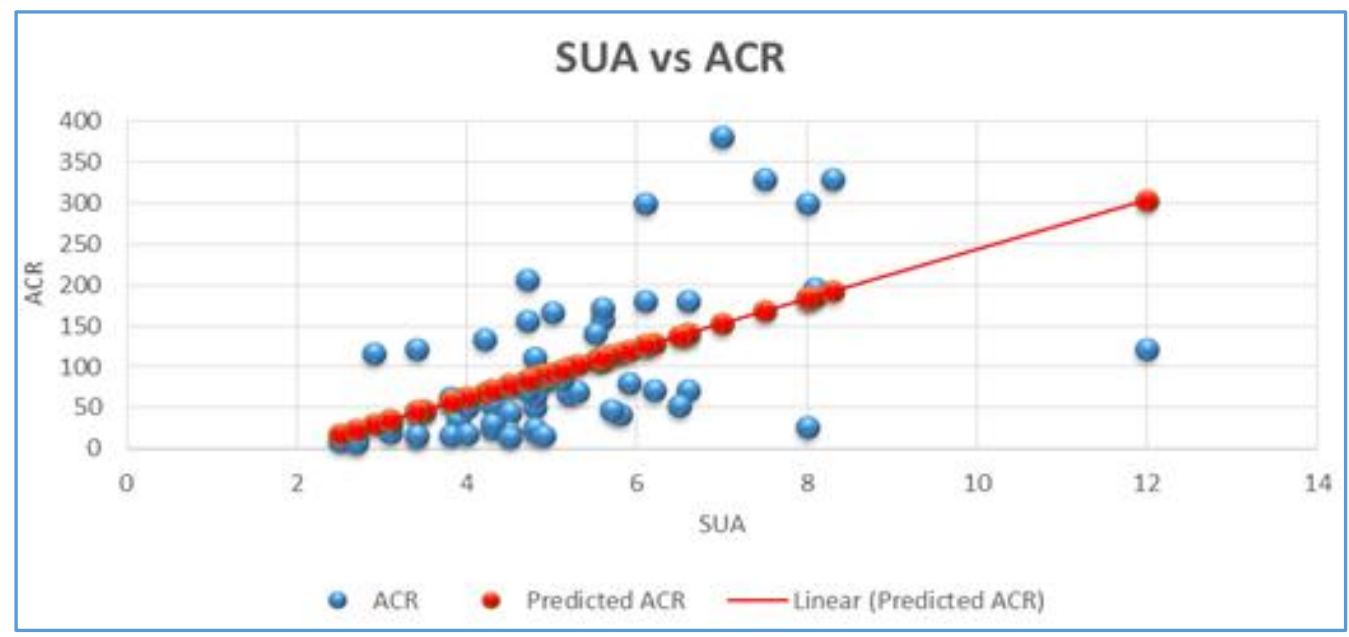

Graph 2: Scattered plot of predicting ACR using SUA 
By multiple regression, considering all variables together they predict $47.2 \%\left(\mathrm{R}^{2}=0.472\right)$ variation in albumin creatinine ratio.

Thus, it showed that serum uric acid was an independent predictor of albumin creatinine ratio, after using adjusted $\mathrm{R}^{2}$ value.

\section{DISCUSSION}

A cross-sectional study was done in 56 type 2 diabetic patients attending the outpatient department and being admitted to our hospital from December 2013 to July 2015. And the relationship between serum uric acid concentration and degree of urinary albumin excretion in type 2 diabetic patients was evaluated.

In this study, a positive correlation was found between serum uric acid and albumin creatinine ratio. In the study conducted by Fukui, et al. positive correlation of serum uric acid and urinary albumin excretion in 343 men with type 2 diabetes mellitus was shown. ${ }^{7}$ Similarly, Fu et al. in a study on Chinese diabetic patients found that hyperuricemia was significantly associated with abnormal albuminuria in patients without diuretics or use of uricosuric agents or alcohol. ${ }^{16} \mathrm{Siu}$ and colleagues reported lowering serum uric acid level in patients with hyperuricemia was associated with regression of kidney disease. 5

In this study, it was found that duration of diabetes and systolic blood pressure was significantly associated with albumin creatinine ratio. Mogensen. ${ }^{17}$ had concluded that age, diabetes duration, glycemic control, blood pressure and metabolic syndrome were all associated with albuminuria and decline of GFR.

Studies in rats showed that the renal changes can be prevented by maintaining SUA levels in the normal range by allopurinol.18,19 but only partially prevented by the treatment of hypertension with enalapril or lorsartan.19-21 These observations suggested that a pathogenic role of uric acid in the renal abnormalities independent of blood pressure and imply a possible efficacy to lower urinary albumin-tocreatinine ratio in diabetic patients by bringing down the uric acid levels. A recent human study did prove that allopurinol treatment could normalize endothelial dysfunction in type 2 diabetic patients with mild hypertension. ${ }^{22}$

This study suggested the importance of uric acid as a predictor of albuminuria in type 2 diabetic patients. The pathogenic role of serum uric acid in renal injury and in increasing urinary albumin excretion rate is worthy of further investigation.

This study had some limitations. The sample size was small. The validity to extrapolate the relationship between uric acid and urinary albumin excretion rate to non-diabetic subjects requires confirmation. As this was a cross-sectional study, further prospective studies should be made to evaluate the relationship between the serum uric acid and albuminuria in type 2 diabetic patients.

\section{CONCLUSION}

This study showed that the serum uric acid concentration was significantly and positively associated with albuminuria in patients with type 2 diabetes mellitus. It was hypothesized by this study that serum uric acid may play a pathological role in the development of albuminuria in type 2 diabetes mellitus. To approve this hypothesis, study of the effect of lowering uric acid with allopurinol on renal function in diabetic nephropathy patients is suggested in future.

\section{REFERENCES}

1. Atlas of end-stage renal disease. Bethesda: National Institutes of Health, NIDDK; 2005. USRDS 2005 Annual Data Report.

2. KDOQI Clinical Practice Guidelines and Clinical Practice Recommendations for Diabetes and Chronic Kidney Disease. Am J Kidney Dis 2007;49:12-154.

3. Stenvinkel P. Chronic kidney disease: a public health priority and harbinger of premature cardiovascular disease. J Intern Med 2010;268:456-467.

4. Edwards, N Lawrence. The role of hyperuricemia in vascular disorders; current opinion in Rheumatology, Vol 21, Issue 2, Mar 2009;132-137.

5. Siu YP, Leung KT, Tong MK, et al. Use of allopurinol in slowing the progression of renal disease through its ability to lower serum uric acid level. American Journal of Kidney Diseases, Vol 47(1), Jan 2006, p 51-59.

6. Bonakdaran S, Hami M, Shakeri MT. Hyperuricemia and albuminuria in patients with type 2 diabetes mellitus. Iran J Kidney Dis 2011;5:21-24.

7. Fukui M, Tanaka M, Shiraishi E, et al. Serum uric acid is associated with microalbuminuria and subclinical atherosclerosis in men with type 2 diabetes mellitus. Metabolism 2008;57:625-629.

8. Humans M, Geeraet B, De Keyzer D, et al. Interleukin-1 receptor-associated kinase-3 is a key inhibitor of inflammation in obesity and metabolic syndrome. PLoS ONE 2012;7:e30414.

9. Goldberg RB. Cytokine and cytokine-like inflammation markers, endothelial dysfunction and imbalanced coagulation in development of diabetes and its complications. J Clin Endocrinol Metab 2009;94:31713182.

10. Lim $\mathrm{AK}$ and Tesch GH. Inflammation in diabetic nephropathy. Mediators Inflamm 2012;2012:146-154.

11. Akbas EM, Demirtas L, Ozcicek A, et al. Association of epicardial adipose tissue, neutrophil-to-lymphocyte ratio and platelet-to-lymphocyte ratio with diabetic nephropathy. Int J Clin Exp Med 2014;7:1794-1801.

12. Valle M, Martos R, Canete MD, et al. Association of serum uric acid levels to inflammation biomarkers and endothelial dysfunction in obese prepubertal children. Pediatr Diabetes 2015;16:441-447.

13. Hung CC, Tsai JC, Kuo HT, et al. Dyslipoproteinemia and impairment of renal function in diabetic kidney disease: an analysis of animal studies, observational studies and clinical trials. Rev Diabet Stud 2013;10:110-120.

14. Kosugi T, Nakayama T, Heinig M, et al. The effect of lowering uric acid on renal disease in the type 2 diabetic db/db Mice. Am J Physiol Renal Physiol 2009;297:481488.

15. Ramachandran A, Snehalatha C. Epidemiology and basic considerations of diabetes. In: Munjal YP, Sharma SK, Agarwal AK, Gupta P, Kamath SA, Nadkar MY, et al. editors. API Textbook of Medicine, 9th ed. Mumbai: Jaypee Brothers; 2012, P 321-323. 
16. Fu CC, Wu DA, Wang JH, et al. Association of C-reactive protein and hyperuricemia with diabetic nephropathy in Chinese type 2 diabetic patients. Acta Diabetol 2009;46:127-34.

17. Mogensen CE. Microalbuminuria, blood pressure and diabetic renal disease: Origin and development of ideas. Diabetologia 1999;42:263-285.

18. Sanchez-Lozada LG, Tapia E, Avila-Casado C, et al. Mild hyperuricemia induces glomerular hypertension in normal rats. Am J Physiol Renal Physiol 2002;283:F1105-F1110.

19. Nakagawa T, Mazzali M, Kand DH, et al. Hyperuricemia causes glomerular hypertrophy in the rat. Am J Nephrol 2003;23:2-7.
20. Mazzali M, Hughes J, Kim YG, et al. Elevated uric acid increases blood pressure in the rat by a novel crystalindependent mechanism. Hypertension 2001;38:110-6.

21. Mazzali M, Kanellis J, Han L, et al. Hyperuricemia induces a primary renal arteriolopathy in rats by a blood pressure-independent mechanism. Am J Physiol Renal Physiol 2002;282:991-7.

22. Bakker SJ, Gans RO, Maaten JC, et al. The potential role of adenosine in the pathophysiology of the insulin resistance syndrome. Atherosclerosis 2001;155:283290. 